\title{
A Study on an Automatic Welder with the New-Type Spiral Heat Exchanger's Pillar Plate
}

\author{
Xingtian $\mathrm{Qu}^{1, \mathrm{a}}$, Kun Zhang ${ }^{2, \mathrm{~b}}$, Yuzhe Wang ${ }^{3, \mathrm{c}}$, Jinghui Peng ${ }^{4, \mathrm{~d}}$, Wenqiang $\mathrm{Xu}^{5, \mathrm{e}}$, \\ Wang Xuexu,f
}

\author{
${ }^{1,2,3,4,5,6}$ Mechanical Science and Engineering, Jilin University, Changchun, china 130025 \\ aquxt@jlu.edu.cn, b1465625059@qq.com, c490987516@qq.com, d1518986612@qq.com, \\ e1160320742@qq.com, ${ }^{\mathrm{f}} 784694722 @ q q . c o m$
}

Keywords: spiral heat exchanger; automatic welder; electric resistance welding; given-distance pillars' holder;

Abstract.This paper mainly studys on a kind of new-type automatic welder - an automatic welder with the new-type spiral heat exchanger's pillar plate, the welding process of given-distance pillars in the production process of spiral heat exchangers is invested and analyzed. This paper analyzes the ultimate principle of electric resistance welding. This automatic welder realizes the accurate positioning of auto filter and welding position for given-distance pillars, ensures welding quality and improves automatic degree of production processing through vibratory screening mechanism, given-distance conveying mechanism, given-distance pusher mechanism, welding mechanism, and welding gun latitude moving mechanism. Moreover, the paper also analyzes the stress situation of given-distance holder by using SolidWorks software.

\section{Introduction}

In recent years, our country has conducted a certain field trip in the overseas market of heat exchangers. It can be found that competitiveness of plate heat exchangers presents a growing trend constantly. However, tubular heat exchanges in various countries still have a larger proportion which accounted for $3 / 5$ of total quantity [1]. The exploitation and design of spiral heat exchangers is developing rapidly. Nevertheless, after studying its production process, it can be found that weld of given-distance pillars adopts manual welding, has lower production efficiency and is easy to take place pseudo soldering and weld penetration. This new-type automatic welder is a whole set of automatic device of realizing given-pillar pillars from screening, transporting to weld. It not only greatly improves production efficiency of spiral heat exchangers, but also avoids from problems of pseudo soldering and welds penetration, so as to ensure its quality.

\section{Theoretical Analysis of Electric Resistance Welding}

The Ultimate Principle of Electric Resistance Welding. Electric resistance welding generates Joule heat for joint parts through currents from electrodes flow to welding the parent metal, so as to rise temperature of the binding site. In most conditions, temperature will rise to the melting state. Basically it is not applicable for welding auxiliary materials for the time being. In the meantime, two electrodes will put pressure on woods continuously, so as to make woods generate plastic deformation, make surface connect tightly, and generate firm joint parts. In butt welding, it generally produces the pressure at the last of welding, and such the pressure is called as upsetting pressure and increases suddenly[2].

The quantity of heat production is transferred due to heat conduction between the parent metal and electrodes, so the temperature of joint parts is rising. As shown in Fig. 1, temperature distribution appeared in joint parts can generate the highest temperature (When conducting sheet spot welding, $90 \%$ of heat has already been transferred, before finishing welding).

There are three conditions of electric resistance welding including welding currents, resistance welding time and electrode pressure. In the electric resistance welding, these conditions have close interaction and connections. 
Peak and Effective Value of Welding Currents. The quantity of heat generated by electric resistance welding is calculated in line with Eq.1 Joule's Law.

$$
Q=I^{2} R t
$$

In Eq.1: $\quad Q$ - quantity of heat (J)

$I$ - welding currents (A)

$R$-resistance between electrodes $(\Omega)$

$t$ - resistance welding time(s)

The resistance R can be calculated by the Eq.2. Resistance between electrodes includes resistance of the artifact $R_{\mathrm{w}}$, contact resistance between two artifacts $R_{\mathrm{c}}$, and contact resistance between electrodes and the artifact $R_{\text {ew }}$.

$$
R=2 R w+R c+2 R e w
$$

In the direct-current main, the calorific value of the direct current I conducted within $t$ seconds is $Q=I^{2} R t$, and calorific value is related to quadratic of currents. The computing method schematic diagram of effective value is shown in Fig. 2.

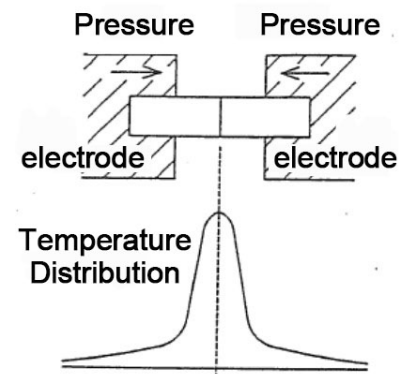

Fig. 1 Temperature Distribution of Joint Parts

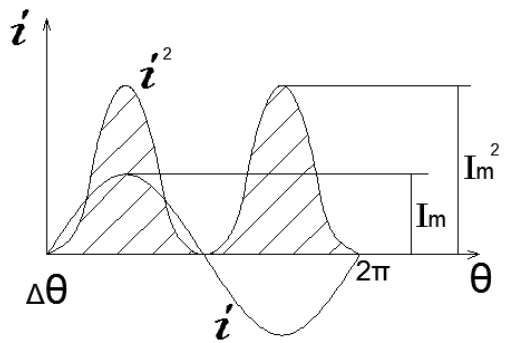

Fig. 2 Computing Method of Effective Value

In the alternating current power supply, $\mathrm{i}=\mathrm{Im} \sin \theta$ refers to alternating currents, $\mathrm{Im}$ is the peak of alternating currents, and calorific value of alternating currents in one period is $Q=\bar{I}^{2} R t, \bar{I}^{2}$ is the mean of $i^{2}$ in one period and can be calculated by the Eq.3.

$$
\bar{I}^{2}=\frac{1}{2} \pi \int_{0}^{2 \pi} i^{2} d \theta=\frac{1}{2} \pi \int_{0}^{2 \pi} I_{m}{ }^{2} \sin \theta d \theta=\frac{1}{2} I_{m}{ }^{2}
$$

Therefore, $\quad \bar{I}=\frac{I_{m}}{\sqrt{2}}$

This $\bar{I}$ is the effective value of alternating currents and is the value after converting direct currents of equivalent quantity of heat.Therefore, the actual current value that operates on calorific value is the effective value measured by welding current value.

\section{The Study on an Automatic Welder with a Spiral Heat Exchanger's Pillar Plate}

The Working Purpose of an Automatic Welder with a Spiral Heat Exchanger's Pillar Plate. The thickness of the spiral plate in a spiral heat exchanger is $4 \mathrm{~mm}$, and width is $1000 \mathrm{~mm}$. The length has no fixed requirement, so it is $2000 \mathrm{~mm}$ temporarily. The material is Q235. The height of a given-distance pillar is $20 \mathrm{~mm}$, the diameter of round pin is $10 \mathrm{~mm}$, and material is 45 steel.

This machine needs to screen out a given-distance pillar, send it to the underface of a welding gun through the conveying mechanism and pusher mechanism accurately, and control the welding gun to weld the given-distance pillar to the spiral plate in the way of electric resistance welding.

Operating Mechanism of an Automatic Welder with a Spiral Heat Exchanger's Pillar Plate. The Fig. 3 is the mechanism diagram of an automatic welder with a spiral heat exchanger. The lathe bed height is $875 \mathrm{~mm}$, lateral width is $2280 \mathrm{~mm}$, length direction has no fixed requirement and is $2000 \mathrm{~mm}$ for temporarily, height of portal frame is $1490 \mathrm{~mm}$, and lateral width is $2880 \mathrm{~mm}$. 




1. Vibratory Screening Mechanism; 2. Portal Frame; 3. Welding Mechanism; 4. Lathe Bed; 5. Welding gun Latitude Moving Mechanism;6. Given-Distance Pusher Mechanism;7.Given-Distance Conveying Mechanism

Fig. 3 Master Drawing of an Automatic Welder with a Spiral Heat Exchanger's Pillar Plate

The Working Principle of an Automatic Welder with a Spiral Heat Exchanger's Pillar Plate. As shown in Fig. 4, it is the working framework of an automatic welder with a spiral heat exchanger's pillar plate. Vibrating disk 1 screens and transports a given-distance pillar to the U groove with cog belt of the given-distance pillar conveying mechanism. The given-pillar conveying mechanism 7 transports the given-distance pillar to the assigned position, and then it stops transferring. The longitudinal air cylinder of the given-distance pillar pusher mechanism starts driving the rear plate, and rear plate drives the rear arm of a holder. This rear arm drives two forearms. The advancement of two forearms makes the L clamping arm clamp the given-distance pillar. Afterwards, under the promotion of longitudinal air cylinder, it keeps on moving until it reaches the underface of the welding gun. Moreover, it limits through the given-distance pillar's stop dog. The resistance welding gun operates and welds the given-distance pillar on the spiral plate, and the lateral air cylinder can be used for adjusting the position of the resistance welding gun.



Fig. 4 Working Framework of an Automatic Welder with a Spiral Heat Exchanger's Pillar Plate

Fig. 5 is the vibratory screening mechanism diagram. Vibrating disk can make the given-distance pillar move from the bottom to the top in the spiral track through the function of vibrating vibrator, reach the topmost discharge track, and drop into the discharge inner tube. The end of vibrating disk discharge track is equipped with a correlation sensor, so as to control the number of dropping out the given-distance pillar. Because the front of discharge hole involves with the front plate in work and pusher mechanism, so that front can move up and down.

Fig. 6 is the given-distance conveying mechanism diagram. The cog belt is driven by the alternating servo motor. There is a rubber brick with $U$ groove. Only the given-distance pillar at the site of 
discharge hole falls to the $\mathrm{U}$ groove can it bring out by the cog belt and transport to the assigned position.

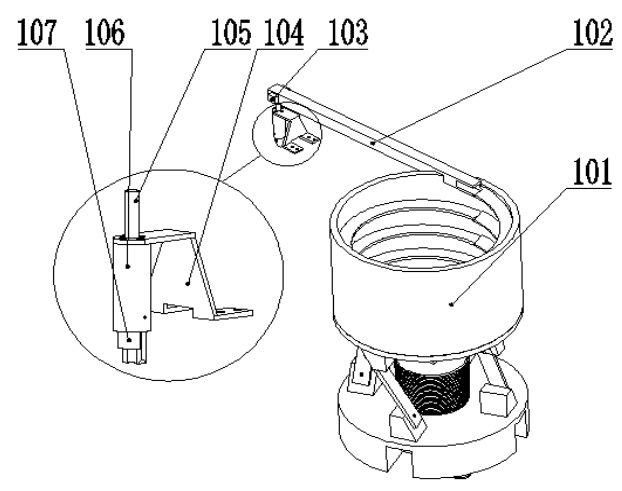

101 Vibrating Disk; 102 Vibrating Disk Discharge Track; 103 Correlation Photoelectric Sensor; 104 Discharge Hole Supporting Seat; 105 Discharge Inner Tube; 106 Discharge External Sleeve; 107 Discharge Front End

Fig. 5 Vibratory Screening Mechanism Diagram

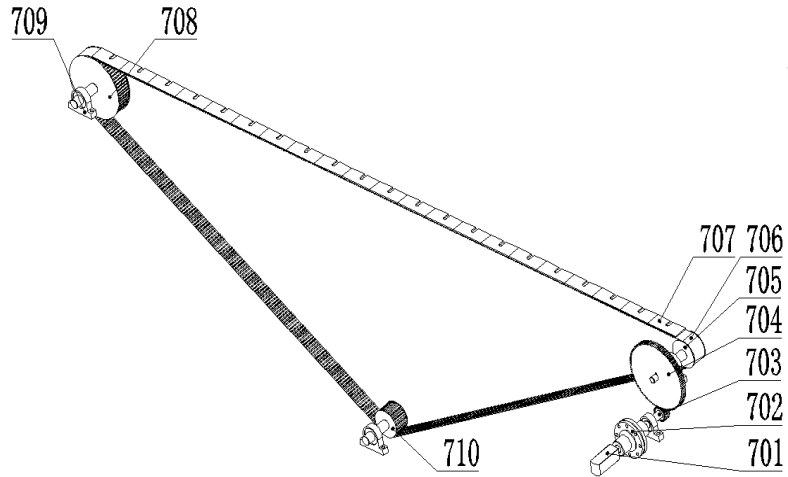

701 Alternating Servo Motor; 702 Elastic Pin Coupling; 703 Gear Shaft ; 704 Rack Wheel; 705 Small Pulley; 706 Cog Belt; 707 U Groove; 708 Big Pulley; 709 Bearing Pedestal; 710 Tensioning Wheel

Fig. 6 The Given-Distance Conveying Mechanism Diagram

Fig. 7 is the given-distance pusher mechanism diagram. The back plate of a holder is pushed forward by longitudinal air cylinder at the stage of clamping the given-distance pillar. The front plate keeps stall under the function spring lock. The clamped air cylinder continues to impose pushing force. In this way, front plate can move forward with the back plate and the holder. When the holder withdraws, the front plate can keep still under the control of spring lock. When it loosens completely, air cylinder continues to impose tensile force and pull it back.

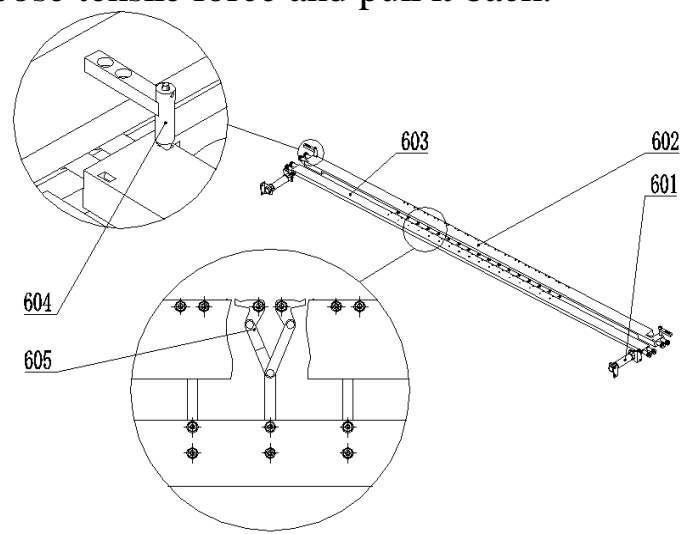

601 Longitudinal Pusher Air Cylinder; 602 Front Plate; 603 Back Plate;604 Spring Lock; 605 The Holder of the Given-Distance Pillar Fig. 7 The Given-Distance Pusher Mechanism Diagram

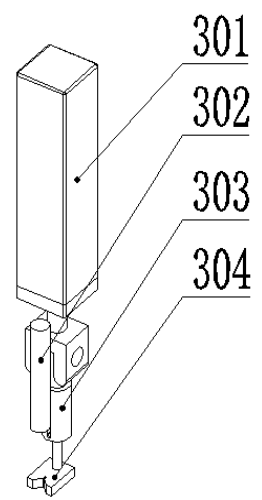

301 Welding Gun Upper Air Cylinder;302 Resistance Welding Gun; 303 The Given-Distance Pillar Block External Sleeve; 304 The Given-Distance Pillar Block

Fig. 8 Welding Mechanism Diagram

Fig. 8 is the welding mechanism diagram. Before the given-distance pillar pusher mechanism pushes, the given-distance pillar block drops firstly and contacts with the spiral plate. After the pusher mechanism sends the given-distance pillar to the underface of resistance welding gun, the falling pressure of the resitance welding gun press the given-distance pillar. The pressure value controls through decreasing valve from the upper air cylinder to make pressure force of all resistance welding guns become identical. 9 resistance welding guns are driven by two welding powers. The resistance welding time is the same.

Fig. 9 is the welding gun latitude moving mechanism diagram. In order to reach the requirement that staggers the given-distance position at two adjacent rows, the supporting plate of air cylinder pusher 
welding gun makes the welding gun moves $60 \mathrm{~mm}$ with the rolling guide. The balance weight plate places a welding gun and pouring supporting plate to reduce the load of a sliding block.

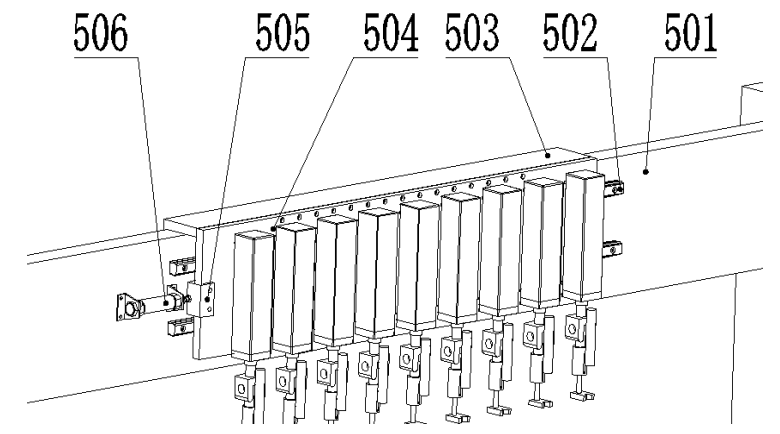

501 Portal Frame Beam; 502 Rolling Guide; 503 Balance Weight Plate; 504 Welding Gun Supporting Plate; 505 Lateral Air Cylinder Front End; 506 Lateral Pusher Air Cylinder

Fig. 9 Welding Gun Latitude Moving Mechanism Diagram

Fig. 10 is the effect picture of welding. There is malposition relation between given-distance pillars in two adjacent rows.

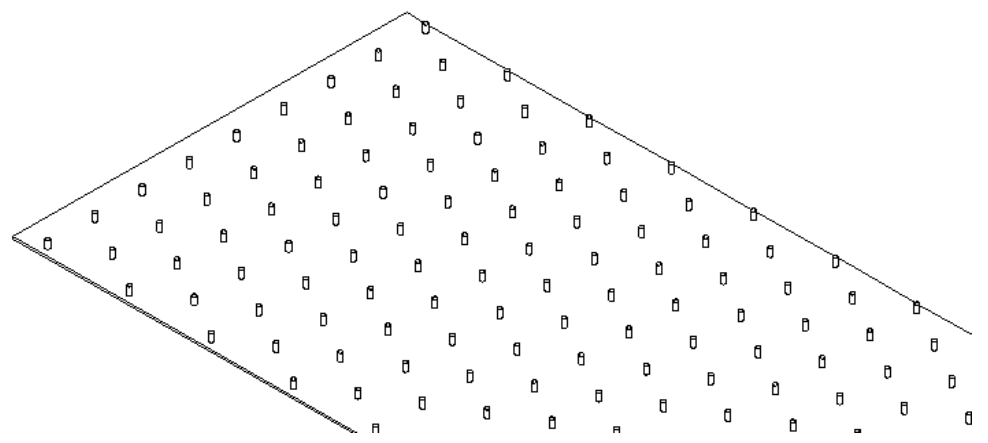

Fig. 10 Effect Picture of Welding

The Finite Element Analysis of $\mathbf{L}$ Holder of the Given-Distance Holder. Fig. 11 is the given-distance holder diagram. We calculate the biggest clamp force of $\mathrm{L}$ holder arm in the work and make use of SolidWorks to analyze its stress distribution and small deformation under the force of it.

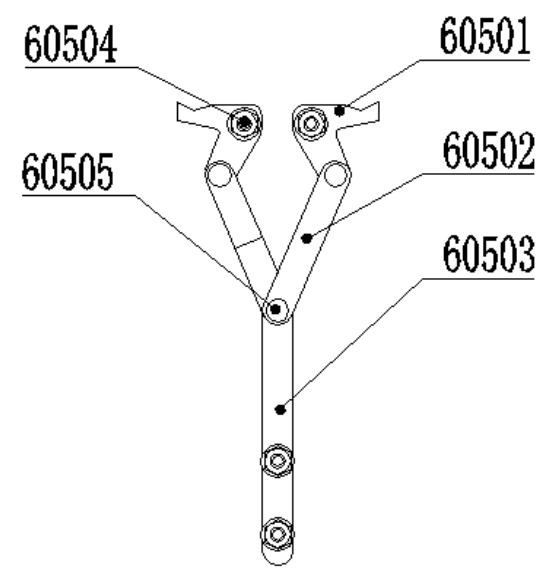

60501 L Holder Arm; 60502 Holder Forearm; 60503 Holder Rear Arm; 60504 Hexagon Bolt; 60505 Pin

Fig. 11 The Given-Distance Pillar Conveying Mechanism Diagram

Because the biggest spring deformation in the discharge hole forms the component force of elastic force makes the pushing force become $62 \mathrm{~N}$ in two longitudinal directions, at least there are 8 holders to work. Therefore, every holder receives the biggest pushing force $\mathrm{F}_{0}=7.75 \mathrm{~N}$. The stress analysis is shown in Fig. 12 




(a)

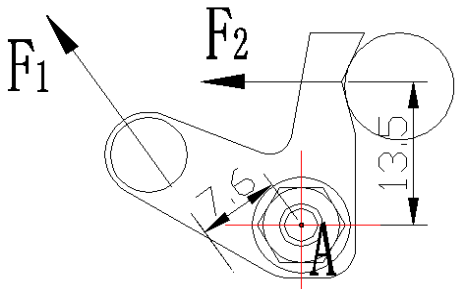

(b)

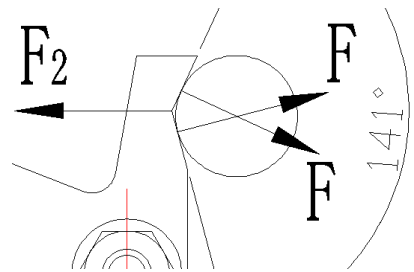

(c)

Fig. 12 Stress Analysis

As shown in Fig. 12 (a): $2 F_{1} \cos 35^{\circ}=F_{0}$, In the Fig. 12(b), Point $\mathrm{A}$ is the base point and moment is 0 , it can be observed that: $F_{1} \times 7.6=F_{2} \times 13.5$. From the Fig.12 (c), it can be observed that: $2 F \cos 70.5^{\circ}=F_{2}$. To sum up: $F=4 N$.

After solving the above force, the L holder arm model is established. Moreover, it divides the gridding and sets up boundary types. The material is 45 steels. The normal force imposed at both sides is $4 \mathrm{~N}$. The animated simulation is shown in Fig. 13-The analysis of static stress and static displacement.



(a)

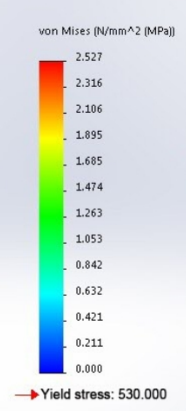

(b)

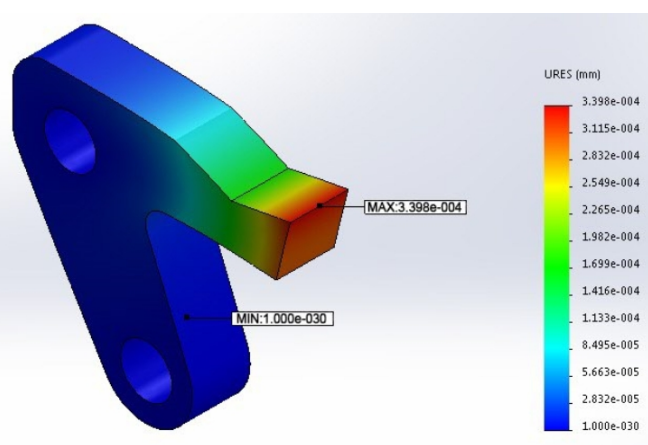

(b)

Fig. 13 The Analysis of L Holder Arm's Static Stress and Static Displacement

It can be observed from Fig.13(a) that the biggest stress is $2.527 \mathrm{MPa}$ and gradually reduces downward. It can be observed from Fig.13(b) that the biggest deformation is $3.398^{*} 10^{-4} \mathrm{~mm}$. Both of them are kept in the safe range.

\section{Conclusion}

The automatic welding with a spiral heat exchanger's pillar plate realize screening and accurate position of the given-distance pillar, improve production efficiency and quality of a spiral heat exchanger remarkably, and step forward automatic production with the help of vibrating screening mechanism, the given-distance conveying mechanism, pusher mechanism, welding mechanism, and welding gun latitude moving mechanism to

\section{Reference}

[1]Q.J. Huang, J.C. Ren. Petroleum \& Chemical Equipment in chinese.2010,01:5-8.

[2]Oshima Kenji. Electric Resistance Welding Q\&A in japanese [M]. Japan: Welding Society of Japan,2002:9-12. 